PREPARED FOR THE U.S. DEPARTMENT OF ENERGY, UNDER CONTRACT DE-AC02-76CH03073

PPPL-3601

PPPL-3601

UC-70

NSTX Diagnostics and Operation: Status and Plans

by

M.G. Bell, R.E. Bell, B.P. LeBlanc, S.S. Medley

and the NSTX Research Team

August 2001

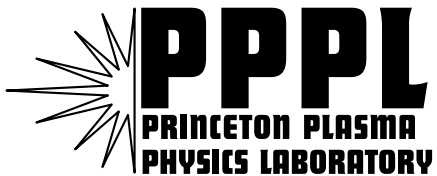

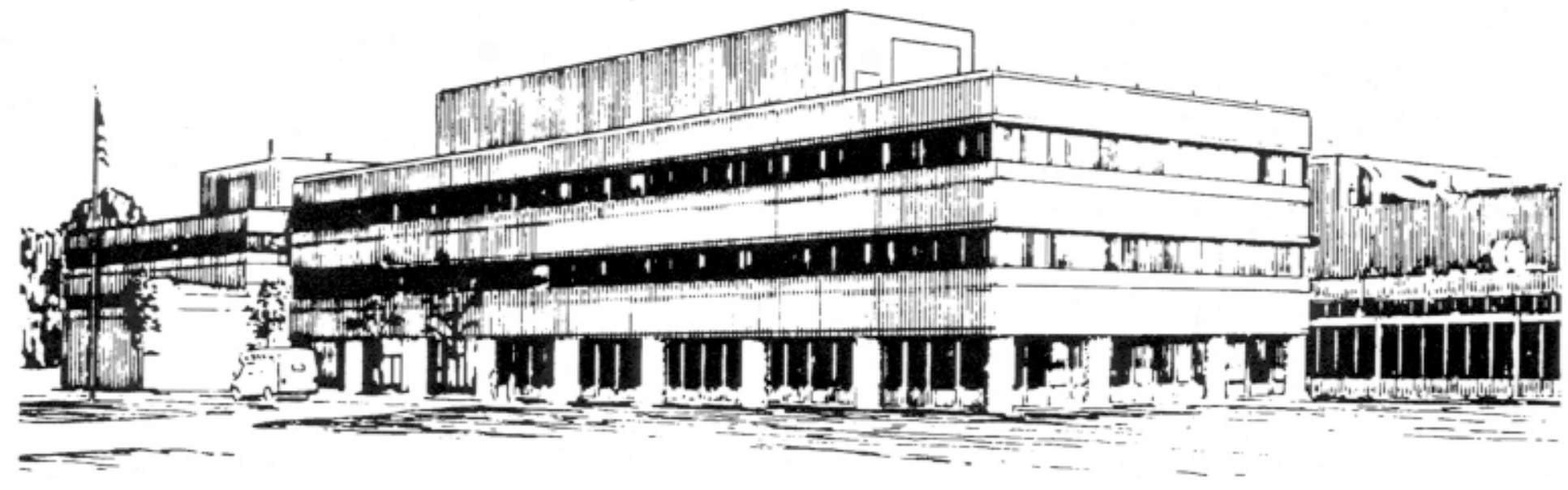

PRINCETON PLASMA PHYSICS LABORATORY PRINCETON UNIVERSITY, PRINCETON, NEW JERSEY 


\section{PPPL Reports Disclaimer}

This report was prepared as an account of work sponsored by an agency of the United States Government. Neither the United States Government nor any agency thereof, nor any of their employees, makes any warranty, express or implied, or assumes any legal liability or responsibility for the accuracy, completeness, or usefulness of any information, apparatus, product, or process disclosed, or represents that its use would not infringe privately owned rights. Reference herein to any specific commercial product, process, or service by trade name, trademark, manufacturer, or otherwise, does not necessarily constitute or imply its endorsement, recommendation, or favoring by the United States Government or any agency thereof. The views and opinions of authors expressed herein do not necessarily state or reflect those of the United States Government or any agency thereof.

\section{Availability}

This report is posted on the U.S. Department of Energy's Princeton Plasma Physics Laboratory Publications and Reports web site in Calendar Year 2001. The home page for PPPL Reports and Publications is: http://www.pppl.gov/pub_report/

DOE and DOE Contractors can obtain copies of this report from:

U.S. Department of Energy

Office of Scientific and Technical Information

DOE Technical Information Services (DTIS)

P.O. Box 62

Oak Ridge, TN 37831

Telephone: (865) 576-8401

Fax: (865) 576-5728

Email: reports@adonis.osti.gov

This report is available to the general public from:

National Technical Information Service

U.S. Department of Commerce

5285 Port Royal Road

Springfield, VA 22161

Telephone: 1-800-553-6847 or

(703) 605-6000

Fax: (703) 321-8547

Internet: http://www.ntis.gov/ordering.htm 


\title{
NSTX Diagnostics and Operation: Status and Plans ${ }^{1}$
}

\author{
M.G. Bell, R.E. Bell, B.P. LeBlanc, S.S. Medley and the \\ NSTX Research Team \\ Plasma Physics Laboratory, Princeton University, Princeton, NJ, U.S.A \\ Preprint of a paper to appear in the Proceedings of the Joint Meeting of the \\ Second IAEA Technical Committee Meeting On Spherical Tori \\ and the \\ Seventh International Spherical Torus Workshop \\ National Space Research Institute \\ Sao Jose dos Campos, SP, Brazil
}

1-3 August 2001

\begin{abstract}
The low aspect ratio and low magnetic field of the National Spherical Torus Experiment (NSTX) create many challenges for plasma diagnostics and control as well as opportunities for studying new plasma phenomena. This paper describes the diagnostics now installed for studies of confinement, stability and edge plasma phenomena and some of the diagnostic developments planned for the near future. The design of the plasma control system and plans for its development are also presented.
\end{abstract}

\footnotetext{
${ }^{1}$ Work suported by US Department of Energy Contract DE-AC02-76CH03073
} 


\section{NSTX Diagnostics and Operation: Status and Plans}

The National Spherical Torus Experiment (NSTX), designed for studying toroidal plasma confinement at very low aspect-ratio, can produce plasmas with aspect ratio $\mathrm{A}=\mathrm{R} / \mathrm{a}=$ $0.85 \mathrm{~m} / 0.68 \mathrm{~m} \sim 1.25$, elongation up to 2.2 and triangularity up to 0.5 [1]. The low aspect ratio and low magnetic field $\left(\mathrm{B}_{\text {tor }} \leq 0.6 \mathrm{~T}\right.$ on axis) of NSTX create many challenges for plasma diagnostics and control as well as opportunities for studying new plasma phenomena.

Following the achievement of the first plasma in February 1999, two major experimental campaigns have been conducted. The plasma current, which was brought to its design value of 1 MA in 1999, has recently (May 2001) been increased to 1.4 MA. Plasma heating by both high-harmonic fast waves (HHFW) and neutral beam injection (NBI) has been studied [2]. Toroidal currents up to $400 \mathrm{kA}$ have been generated by coaxial helicity injection (CHI) [3].

For determining the equilibrium, NSTX is equipped with a comprehensive set of flux loops and magnetic field detectors (Mirnov coils) surrounding the plasma. The signals from a subset of these are used in real-time for control of the plasma current, position and shape while digitized data from the full set is used in off-line analysis of the plasma equilibrium with the EFIT code [4]. In the interval between plasma shots $(\sim 10 \mathrm{~min})$, the EFIT analysis provides both global parameters, such as the plasma energy, internal inductance and ohmic power as functions of time with a timestep as small as $1 \mathrm{~ms}$, and the internal flux surface configurations which are then used to map data from other diagnostics into flux coordinates. In future, kinetic measurements of the components of the plasma pressure $\left(\mathrm{n}_{\mathrm{e}}, \mathrm{T}_{\mathrm{e}}\right.$ etc. $)$ will supplement the magnetic data input to EFIT allowing subsequent analysis of the MHD stability.

The Mirnov coils are also used in combination with arrays of ultra-soft x-ray detectors for characterizing MHD instabilities. Some of the Mirnov coils have signal conditioning and data acquisition capable of measuring fluctuations up to $2 \mathrm{MHz}$ in frequency. For detecting low frequency and stationary magnetic perturbations ("locked modes"), a set of six external largearea coils has been installed around the outboard midplane to measure the perturbed radial field. The x-ray detector arrays view the plasma in 4 fans each with 16 lines of sight through the plasma poloidal cross-section at two different toroidal angles. Thin filter foils can be placed over the entrance apertures of the arrays to change the lower limit to the energy range so that it is possible to discriminate edge from central MHD perturbations. Density fluctuations at frequencies up to several $\mathrm{MHz}$ are detected by a frequency-scanning microwave reflectometer which probes the region of the plasma where the density is in the range $(0.2-3.1) \times 10^{19} \mathrm{~m}^{-3}$. A second microwave reflectometer suitable for densities characteristic of the plasma edge, views the plasma through the RF coupler for studies of the wave coupling during HHFW heating. The spatial structure of density fluctuations at the plasma boundary is being studied by imaging the visible emission from the edge region with a fast $(10 \mu \mathrm{s}$ exposure, $1 \mathrm{kHz}$ frame rate) filtered camera. The emission is produced by a small localized gas puff directed at the edge by a line of nozzles, using a helium puff for deuterium plasmas, or vice versa, to distinguish the emission resulting from the puff from the background recycling light.

A dedicated array of ultra-soft x-ray detectors sensitive to radiation down to $\sim 10 \mathrm{eV}$ in energy viewing the plasma tangentially across the midplane is used to measure the power radiated. The local radiated power density is obtained by inversion of the chordal data. The total radiated power, which has generally remained small, typically less than $25 \%$ of the total input power. Spectrometers, broad-band bolometers and filtered detectors spanning altogether the range from the near IR to the VUV characterize impurities and measure the effective ion charge $Z_{\text {eff }}$. 
Since the completion of coverage of the plasma facing surfaces by graphite tiles and the routine application of surface boronization, carbon is the dominant intrinsic impurity, although small amounts of metal impurities have been observed following HHFW heating experiments when the plasma surface had been positioned close $(\sim 2 \mathrm{~cm})$ to the antenna shield at the outboard midplane. In general NSTX now operates with a $Z_{\text {eff }}$ in the range of $1.5-2$ for reference $0.8 \mathrm{MA}$ deuterium plasmas with an average density $\left\langle\mathrm{n}_{\mathrm{e}}\right\rangle \sim 2 \times 10^{19} \mathrm{~m}^{-3}$. In high density helium plasmas, the $\mathrm{Z}_{\text {eff }}$ approaches 2 , confirming the reliability of the measurement.

The profiles of the electron temperature and density are measured as functions of time in each shot by a multi-pulse Thomson-scattering system. At present this system measures at 10 radial locations on the midplane of the vacuum vessel with a concentration of measurement points on the outboard side of the magnetic axis for the normal plasma configuration. Two Nd-YAG lasers each pulsing at $30 \mathrm{~Hz}$ are used and the two pulse trains can be separated by as little as $0.4 \mathrm{~ms}$ for diagnosing reproducible transient phenomena. The very high throughput detection system, using low- $f$-number collection, fiber-optical transmission, interference filters and avalanche photodiode detectors, minimizes the statistical uncertainties. The system is capable of accurate measurements of the electron temperature from less than $5 \mathrm{eV}$ to greater than $5 \mathrm{keV}$ for plasma densities ranging from less than $1 \times 10^{18} \mathrm{~m}^{-3}$ to more than $1 \times 10^{20} \mathrm{~m}^{-3}$. Absolute calibration of the density measurement for each channel is performed by Rayleigh scattering measurements in situ while the vacuum vessel is filled with purified nitrogen gas to an accurately measured pressure of about $250 \mathrm{~Pa}$. The line-integral of the density measured by Thomson scattering has been confirmed by a $2 \mathrm{~mm}$ microwave interferometer in quiescent discharges and, more recently, by measurements with the first chord of a $119 \mu \mathrm{m}$ far-infrared multi-chord interferometer and polarimeter system. High central electron temperatures, $\mathrm{T}_{\mathrm{e}}(0)$ up to $3.7 \mathrm{keV}$, have been measured during heating of moderate-density $\left(\mathrm{n}_{\mathrm{e}}(0) \sim 2 \times 10^{19} \mathrm{~m}^{-3}\right)$ deuterium plasmas by HHFW at power levels of $3-4 \mathrm{MW}$ as seen in Fig. 1. Confirmation of the electron temperature for selected discharges has been provided by pulse-height analysis of the soft $\mathrm{x}$-ray spectrum for $\mathrm{T}_{\mathrm{e}}(0)$ in the range $2-3 \mathrm{keV}$, and by measurements with a highresolution crystal spectrometer of the ratios of $\mathrm{X}$-ray satellite lines from highly-ionized argon $(\mathrm{ArXV}-\mathrm{ArXVII})$ for $\mathrm{T}_{\mathrm{e}}(0)$ in the range $0.8-2 \mathrm{keV}$.

The profiles of the ion temperature and the toroidal rotation of the plasma are measured by spectroscopy of the emission from intrinsic carbon impurities $\left(\mathrm{C}^{5+}\right)$ excited by charge-exchange with the NBI used for plasma heating (CHERS). The interim system now deployed provides data at 14 radial locations. To separate the chargeexchange emission containing the information about the spatial profiles from the intrinsic emission, which comes mainly from near the plasma edge, one of the three

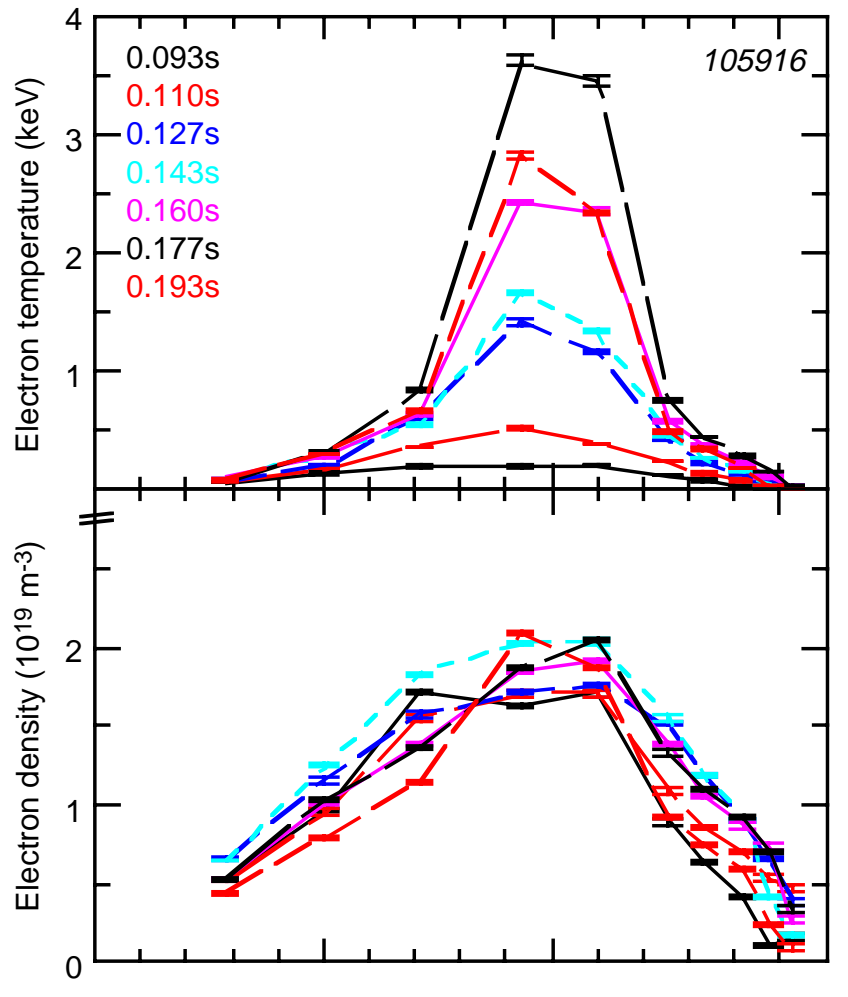

Fig. 1. Profiles of the electron temperature and density measured by Thomson scattering during 3.4MW HHFW heating of a deuterium plasma. $B_{T}=0.45 T, I_{p}=0.9 M A$. 


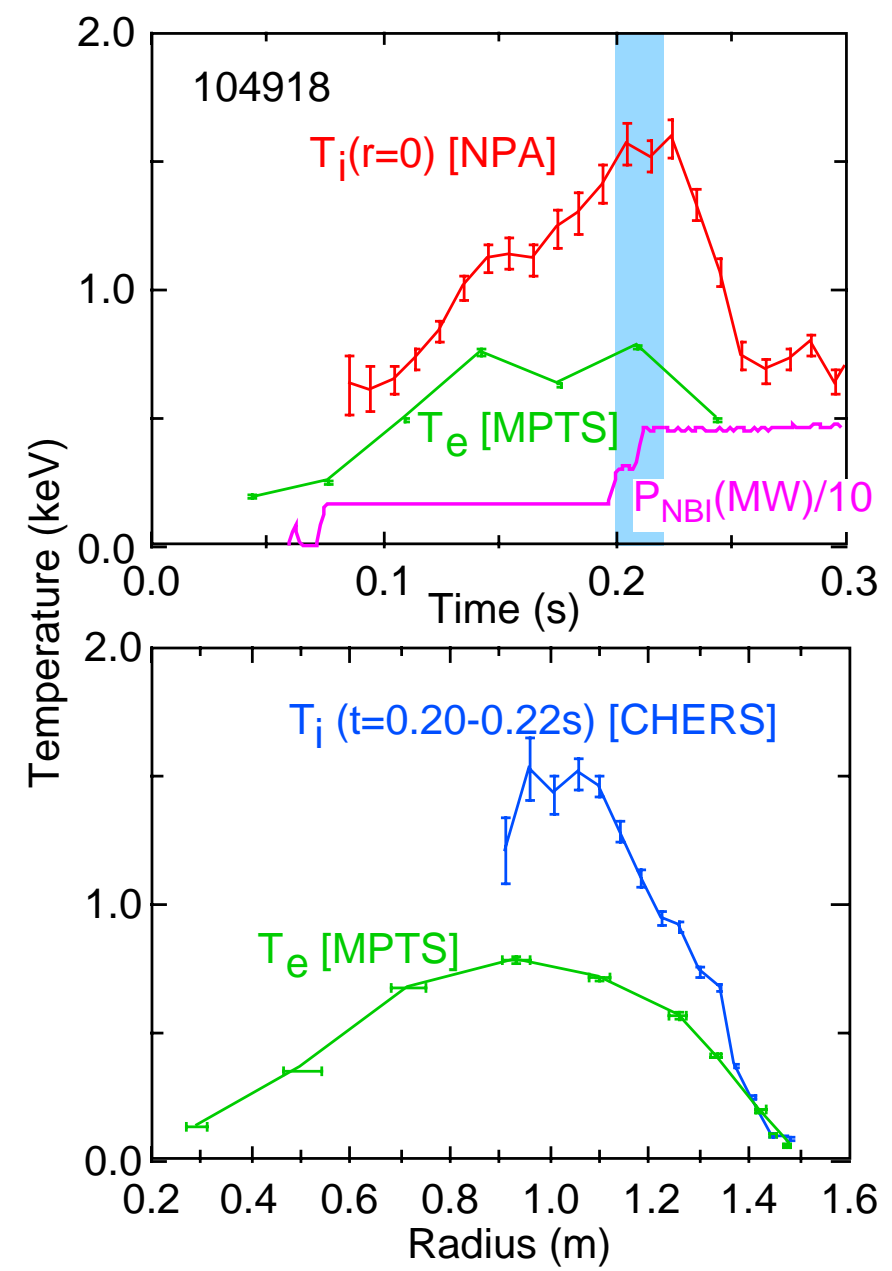

Fig. 2. Ion temperature vs. time from the NPA and vs. radius from CHERS during $N B I . B_{T}=0.4 T, I_{p}=1.25 M A$. neutral beam sources is switched on and off for $20 \mathrm{~ms}$ periods and difference spectra are computed. High ion temperatures, $\mathrm{T}_{\mathrm{i}}(0)$ up to $2.2 \mathrm{keV}$, and rapid toroidal rotation, $\mathrm{v}_{\text {tor }}(0)$ up to $240 \mathrm{~km} / \mathrm{s}$, have been measured during NBI. Both $T_{i}$ and $v_{\text {tor }}$ profiles have regions with large spatial gradients suggesting the creation of internal transport barriers. The central ion temperatures have been confirmed by measurements of the energy spectrum of charge-exchange neutral hydrogen (present as an intrinsic impurity) and by the Doppler width of ArXVII line emission measured by the x-ray crystal spectrometer. Examples of the ion temperature during NBI are shown in Fig. 2. The neutral particle analyzer can also measure charge-exchange deuterium in the energy range $10-100 \mathrm{keV}$ which yields information about the confinement and thermalization of the energetic deuterons from NBI heating. Complementary data on energetic ions lost from the plasma by scattering onto unconfined orbits are obtained from ion collection probes outside the plasma.

The measurements of the kinetic profiles $\left(\mathrm{n}_{\mathrm{e}}, \mathrm{T}_{\mathrm{e}}, \mathrm{T}_{\mathrm{i}}, \mathrm{P}_{\mathrm{rad}}\right)$, the $\mathrm{Z}_{\text {eff }}$ and the EFIT equilibrium, together with data on the auxiliary heating (NBI and HHFW), are being used in analysis of the plasma transport with the TRANSP code. Within the limitations of the applicable plasma and heating models, this code provides consistency checks for data from different diagnostics, particularly between kinetic and magnetic measurements of the plasma energy, as well as calculations of the plasma transport coefficients for comparison with theory.

Several diagnostics for the plasma boundary are now in operation. In particular, the first timeresolved measurements of the heat deposition onto the HHFW coupler and the lower divertor tiles have recently been obtained. The latter will be combined with data from fixed Langmuir probes in the divertor tiles and high spatial resolution measurements of the deuterium Lymanalpha emission on a radial line across the lower divertor tiles to begin characterizing heat and particle fluxes in the scrape-off plasma, issues critical for the future development of STs.

\section{Planned Diagnostic Upgrades}

Within the next year, several diagnostics will have channels added, including Thomson scattering (to 20 channels), the FIR interferometer/polarimeter (to 4 channels), the CHERS diagnostic for $\mathrm{T}_{\mathrm{i}}$ and $\mathrm{v}_{\text {tor }}$ (to 75 channels) and the USXR arrays (to 80 channels). The neutral particle analyzer will have 2D scanning of its line of sight added and a new detector will be installed to make energy and pitch-angle resolving measurements of the escaping ions. 
Critical to the assessment of both plasma stability and non-inductive current drive in the ST is measuring the plasma current profile. Current drive by both the HHFW, when launched with the appropriate phase velocity, and CHI are active research areas for NSTX. The motional Stark effect for both collisionally excited impurity fluorescence (CIF) and eventually laser induced fluorescence (LIF) of injected neutrals will be used to determine both the local poloidal magnetic field and the radial electric field in NSTX. The latter may play a critical role in controlling the transport associated with microinstability turbulence. In the next year, the first two of 10 eventual channels for the CIF-MSE system will be installed. Development of the LIF system is now in progress in the laboratory.

A fast reciprocating probe drive will be installed for measuring both average and fluctuating plasma quantities in the edge and scrape-off. This drive will also accommodate a probe to study the fluctuations accompanying the "plasma dynamo" process believed to be responsible for generation of current on closed magnetic surfaces during $\mathrm{CHI}$. The present measurements of edge plasma parameters and fluxes will be supplemented by additional cameras and views.

In the longer term, diagnostics for measuring the turbulence itself within the plasma core are being planned and developed, including 2D imaging of the density fluctuations with microwave reflectometry. An ultra-fast $(\mathrm{MHz})$ camera for $\mathrm{x}$-ray imaging of the plasma core will be installed to study MHD perturbations.

\section{Plasma Control Upgrades}

The NSTX plasma control system uses real-time digital processing of engineering and plasma diagnostic measurements to control the coil currents [5]. At present, the system utilizes only a subset of the magnetic measurements and regulates by feedback only the plasma current, axial position and the outer gap to the first wall; the plasma shape (elongation, triangularity, etc.) is determined by programmed currents in the poloidal field coils. This has been adequate for the initial experiments and enabled us to produce plasmas with $\beta_{\mathrm{T}}$ as high as $25 \%\left(=2 \mu_{0}<\mathrm{p}>/ \mathrm{B}_{\mathrm{T} 0}{ }^{2}\right.$ where $\mathrm{B}_{\mathrm{T} 0}$ is the vacuum toroidal field at the plasma center). However, in order to reach its ultimate objective of stable high-beta $\left(\beta_{\mathrm{T}} \sim 40 \%\right)$ plasmas for longer than the resistive diffusion timescale $(>1 \mathrm{~s})$, control of plasma profiles using a variety of tools, including the configuration, fueling sources, heating and current drive, will be required. To achieve this, real-time analysis of the plasma equilibrium, including profile data from diagnostics must be implemented. The next phase of the control development is to include all magnetic diagnostic data and to use equilibrium analysis (real-time solution of the Grad-Shafranov equation) for control of multiple gaps and shape parameters. This is planned for the 2002 operational period.

\section{Acknowledgements}

Many physicists and engineers from PPPL and other institutions have contributed to the development and operation of the diagnostics and control system for NSTX. This work is supported by U.S. Department of Energy Contract DE-AC02-76CH03073 and contracts with other institutions developing diagnostics for use on NSTX.

\section{REFERENCES}

[1] S.M. Kaye et al., Phys. Plasmas 8, 1977 (2001)

[2] M. Ono et al., this conference

[3] B. Nelson et al., this conference

[4] S.A. Sabbagh, S. Kaye, J. Menard, et al., to be published in Nuclear Fusion

[5] D. Gates, D. Mueller, C. Neumeyer, J. Ferron, IEEE Trans. Nucl. Sci. 47, 222 (2000) 


\section{External Distribution}

Plasma Research Laboratory, Australian National University, Australia

Professor I.R. J ones, Flinders University, Australia

Professor J oão Canalle, Instituto de Fisica DEQ/IF - UERJ , Brazil

Mr. Gerson O. Ludwig, Instituto Nacional de Pesquisas, Brazil

Dr. P.H. Sakanaka, Instituto Fisica, Brazil

The Librarian, Culham Laboratory, England

Library, R61, Rutherford Appleton Laboratory, England

Mrs. S.A. Hutchinson, JET Library, England

Professor M.N. Bussac, Ecole Polytechnique, France

Librarian, Max-Planck-Institut für Plasmaphysik, Germany

J olan Moldvai, Reports Library, MTA KFKI-ATKI, Hungary

Dr. P. Kaw, Institute for Plasma Research, India

Ms. P.J . Pathak, Librarian, Insitute for Plasma Research, India

Ms. Clelia De Palo, Associazione EURATOM-ENEA, I taly

Dr. G. Grosso, Instituto di Fisica del Plasma, Italy

Librarian, Naka Fusion Research Establishment, J AERI, J apan

Library, Plasma Physics Laboratory, Kyoto University, J apan

Research Information Center, National Institute for Fusion Science, J apan

Dr. O. Mitarai, Kyushu Tokai University, J apan

Library, Academia Sinica, Institute of Plasma Physics, People's Republic of China

Shih-Tung Tsai, Institute of Physics, Chinese Academy of Sciences, People's Republic of China

Dr. S. Mirnov, TRINITI, Troitsk, Russian Federation, Russia

Dr. V.S. Strelkov, Kurchatov Institute, Russian Federation, Russia

Professor Peter Lukac, Katedra Fyziky Plazmy MFF UK, Mlynska dolina F-2, Komenskeho Univerzita, SK-842 15 Bratislava, Slovakia

Dr. G.S. Lee, Korea Basic Science Institute, South Korea

Mr. Dennis Bruggink, Fusion Library, University of Wisconsin, USA

Institute for Plasma Research, University of Maryland, USA

Librarian, Fusion Energy Division, Oak Ridge National Laboratory, USA

Librarian, Institute of Fusion Studies, University of Texas, USA

Librarian, Magnetic Fusion Program, Lawrence Livermore National Laboratory, USA

Library, General Atomics, USA

Plasma Physics Group, Fusion Energy Research Program, University of California at San Diego, USA

Plasma Physics Library, Columbia University, USA

Alkesh Punjabi, Center for Fusion Research and Training, Hampton University, USA

Dr. W.M. Stacey, Fusion Research Center, Georgia Institute of Technology, USA

Dr. J ohn Willis, U.S. Department of Energy, Office of Fusion Energy Sciences, USA

Mr. Paul H. Wright, Indianapolis, Indiana, USA 
The Princeton Plasma Physics Laboratory is operated by Princeton University under contract with the U.S. Department of Energy.

\author{
Information Services \\ Princeton Plasma Physics Laboratory \\ P.O. Box 451 \\ Princeton, NJ 08543
}

Phone: 609-243-2750

Fax: 609-243-2751

e-mail: pppl_info@pppl.gov

Internet Address: http://www.pppl.gov 